\title{
Multitract percutaneous nephrolithotomy in the management of staghorn stones
}

\author{
Aso Omer Rashid' , Sarwar Noori Mahmood', Aram Karim Amin², Rawa Bapir ${ }^{2,3,4}$ and Noor Buchholz ${ }^{3 *}$
}

\begin{abstract}
Background: Staghorn stones are difficult to manage with a risk of significant renal impairment and urosepsis. Percutaneous nephrolithotomy is the first-line treatment for staghorn stones. Often, multiple access tracts are needed to render the patient stone-free. PCNL has been combined with SWL, flexible URS (ECIRS), and mini-PCNL to access residual fragments without the need of additional tracts. However, in a country with limited access to technology and a restraint on resources, multitract PCNL still is the preferred option. The aim of this study was to assess the safety and efficacy of multitract PCNL in such an environment.
\end{abstract}

Methods: We analyzed data on sixty-five patients with staghorn calculus who underwent multitract PCNL for a staghorn calculus. Data included demographics, stone parameters, intraoperative parameters, complications and clinical outcomes. Hb-drop and creatinine changes were assessed pre- and post-OP. Complications were graded according to the modified Clavien-Dindo classification.

Results: In a total of 65 patients [47 males (72\%)], 154 percutaneous access tracts were used in 66 renal units. The number of tracts varied between 2 and 4 in a single renal unit. The stone-free rate was $85 \% .20 \%$ of patients developed grade I, 14\% grade II, and 3\% grade III b complications. There were no grade IV and V complications.

Conclusion: Multitract PCNL is safe and efficient, with a good stone-free rate and an acceptable complication rate. When auxiliary combination treatments are not available, multitract standard PCNL remains an option.

Keywords: Percutaneous nephrolithotomy, Staghorn stones, Multiple tracts, Complications

\section{Background}

The treatment of staghorn stones is challenging. Due to their high recurrence rates, particularly in infectious stones, complete removal of stone material is mandatory [1].

The estimated five-year recurrence rate is up to $50 \%$ [2]. Staghorn stones, by definition, are branched into two or more calyces. Particularly when the stone burden reaches

\footnotetext{
*Correspondence: noor.buchholz@gmail.com; scientific-Office@u-merge. com

${ }^{3}$ U-merge Ltd. London, Scientific Office, 1 Menandrou Street,

14561 Athens, Greece

Full list of author information is available at the end of the article U-merge Ltd. (Urology for Emerging Countries) is an academic urological platform dedicated to facilitate knowledge transfer in urology on all levels from developed to emerging countries. U-merge Ltd. is registered with the Companies House in London/UK. www.U-merge.com
}

$>2000 \mathrm{~mm}^{2}$, surgical treatment remains technically difficult regardless of the treatment modality used [3].

Different treatment modalities include open surgery, laparoscopy, percutaneous nephrolithotomy (PCNL), multi-staged ureterorenoscopy (URS) in selected cases, and endoscopic combined intrarenal surgery (ECIRS). Some studies suggested that open or laparoscopic surgery is an efficient method for the management of large and complex renal stones associated with a high singlesession stone-free rate $[4,5]$. Notwithstanding the fact that both are more invasive, PCNL can easily be repeated if needed, whereas laparoscopic or open surgery become more complicated after an initial procedure due to anatomical changes and scarring [6].

PCNL is regarded as the treatment of choice for staghorn calculi [7]. Although it has stood the test of time as a minimally invasive, safe, and efficient procedure in 
its various forms, it is associated with an overall complication rate of $25 \%$, usually assessed with the modified Clavien-Dindo classification [8]. The most frequent complications are fever (0-32\%) and bleeding requiring blood transfusion (0-20\%) [9]. Radiation exposure during PCNL is another concern still discussed [10]. Over time, the safety and efficacy of PCNL have improved through various changes and modifications [11]. The introduction of flexible URS and its combination with PCNL (ECIRS) has aided in the most complex cases and, in many instances, abolished the need for multiple punctures [12]. Flexible ureterorenoscopy is however not widely available in the developing world. These scopes are expensive, fragile, of limited lifetime, and require a specific back-up infrastructure (light and camera system, sterilization, disposables, etc.).

Many complex staghorn stones, therefore, do require multiple accesses into various calyces in order to access and remove all parts of the stone [13]. The debate continues whether to do a single tract procedure with a 2nd look PCNL, or sandwich therapy in which initial PCNL is combined with extracorporeal shock wave lithotripsy (SWL) and followed by another 2nd look PCNL, or rather a multitract PCNL in an attempt to render the patient stone-free in one single session. The latter may achieve a stone-free rate of 84-95\% [14]. Moreover, multitract single-session PCNL would bring down costs significantly by avoiding multiple procedures of any kind [15-17]. Multitract PCNL has a similar complication rate compared to combined treatments [18], although some studies suggest multiple tracts as a cause for peri-operative bleeding $[19,20]$.

Most data on multitract PCNL come from well-established stone centers in the developed world [1, 2, 7, 9$12,14,16,17]$. As a developing country, we do not have easy access to multi-modality treatments because they are not available or affordable to the patients, and hence we have to use resources sparingly. Therefore, multitract PCNL remains our treatment of choice in patients with large complex stone burdens. In this study, we assessed whether multitract PCNL is efficient and safe in our hands in terms of stone-free rate and complication-rate. We believe that these data are important for stake-holders in similar economic environments.

\section{Methods}

Ethical approval was obtained from the National Board for Medical Specializations (Urology).

Sixty-five patients who underwent elective PCNL for large and complex staghorn stones between August 2016 and April 2019 were included and prospectively analyzed.
The preoperative workup included complete medical history, physical examination, and laboratory investigations (urinalysis, complete blood count, blood biochemistry, coagulation profile, renal function test, viral markers, and blood group with cross-match). Preoperative imaging included ultrasound-KUB and an unenhanced CT scan in all patients.

Patients with uncontrolled coagulopathy, severe musculoskeletal deformities, pregnancy, and active infections were excluded.

Preoperative data recorded were age, gender, BMI, comorbidities, previous surgeries, site and size of the stone, and the presence of hydronephrosis.

Intraoperative data included the type of anesthesia, number of tracts, tract diameters, point of entry to the collecting system, intraoperative bleeding, extravasation, pelvic and PUJ injury, and operative time.

Postoperatively, blood transfusion, fever, sepsis, thoracic complications, transient hematuria, transient renal function disorder, and stone-free rate were recorded.

All patients were operated by the same highly experienced surgeon in a high-volume stone center with a standard prone PCNL in either spinal or general anesthesia, under prophylactic IV-administration of a thirdgeneration cephalosporin at induction. Access was obtained with fluoroscopy guidance and serial plastic dilators. A F18 standard rigid nephroscope (Karl Storz, Tuttlingen, Germany) and pneumatic lithotripsy were used (NidhiLith, Nidhi Medical systems, Delhi, India). When it was not possible to reach all stones, additional PCNL tracts were laid. The procedure was continued until stone-freeness was confirmed radiologically and optically, or safe continuation had become compromised by impaired vision, mostly through bleeding. All patients had an anterograde JJ stent, a percutaneous nephrostomy (PCN), and a bladder catheter. The latter was removed after $6 \mathrm{~h}$, the PCN after $24 \mathrm{~h}$ unless there was persistent bleeding.

$\mathrm{Hb}$ was measured after $24 \mathrm{~h}$ again, postoperatively. Under the assumption that one transfused unit of blood increases the $\mathrm{Hb}$ by $1 \mathrm{gr} / \mathrm{dL}$, Hb-drop was calculated as:

$$
\begin{aligned}
& \mathrm{Hb} \text { - drop }=(\text { Preoperative } \mathrm{Hb}-\text { postoperative } \mathrm{Hb}) \\
& \quad+(\text { number of units transfused } \\
& \quad \times 1 \mathrm{~g} / \mathrm{dL} \text { Hb per unit transfused })[21]
\end{aligned}
$$

Complications were graded according to the modified Clavien-Dindo system.

Patients were assessed for residual fragments by Xray and US KUB 2 weeks postoperatively. Patients were 
Table 1 Patients $(n=65)$ and stones

\begin{tabular}{|c|c|c|}
\hline Characteristics & Value & Percentage \\
\hline Age, year & $\begin{array}{l}43.24 \pm 13.775 \text { SD } \\
(20-70)\end{array}$ & \\
\hline \multicolumn{3}{|l|}{ Gender } \\
\hline Male & 47 & $72 \%$ \\
\hline Female & 18 & $28 \%$ \\
\hline \multicolumn{3}{|l|}{ Chronic disease } \\
\hline Hypertension & 15 & $23 \%$ \\
\hline Diabetes & 12 & $18 \%$ \\
\hline Both & 5 & $8 \%$ \\
\hline BMI & $26.445 \pm 4.577 \mathrm{SD}$ & \\
\hline \multicolumn{3}{|c|}{ Laterality of stones $(n=66)$} \\
\hline Left & 31 & $47 \%$ \\
\hline Right & 33 & $50 \%$ \\
\hline Bilateral & 1 & $1.5 \%$ \\
\hline \multicolumn{3}{|l|}{ Staghorn } \\
\hline Complete & 41 & $62 \%$ \\
\hline Partial & 25 & $38 \%$ \\
\hline Stone size, mm & $60.06 \pm 18.101$ & $(36-120 \mathrm{~mm})$ \\
\hline \multicolumn{3}{|c|}{ Grade of hydronephrosis } \\
\hline No & 9 & $14 \%$ \\
\hline Mild & 30 & $45 \%$ \\
\hline Moderate & 17 & $26 \%$ \\
\hline Severe & 10 & $15 \%$ \\
\hline \multicolumn{3}{|c|}{ History of previous stone intervention } \\
\hline SWL & 10 & $15 \%$ \\
\hline URS & 9 & $13 \%$ \\
\hline PCNL & 13 & $19 \%$ \\
\hline Open & 25 & $37 \%$ \\
\hline
\end{tabular}

kept on ongoing regular follow-ups and late complications were recorded.

Data were analyzed using the Statistical Package for Social Sciences (SPSS version 25). A paired $T$ test was used for comparative analyses. A $p$ value $<0.05$ was considered statistically significant.

\section{Results}

Data on 65 patients were analyzed in this study, thereof $47(72 \%)$ males. Mean age was $43.2 \pm 13.7$ years $(20$ 70 years). Mean BMI was $26.4 \pm 4.5$. As the most prevalent comorbidities, diabetes mellitus was present in 12 (18\%), high blood pressure in $15(23 \%)$, and a combination of both in $5(8 \%)$.

The mean stone burden was $60 \pm 18 \mathrm{~mm}(36-120 \mathrm{~mm})$. Mild/moderate/severe hydronephrosis was present in $45 / 26 / 15 \%$ of cases, respectively. Half of the stones were in the right kidney. Fifty-seven (88\%) of patients had had previous stone interventions (Table 1 ).

Mean OP time was $79 \pm 25 \mathrm{~min}(55-160 \mathrm{~min})$. The vast majority of patients were operated upon under spinal anesthesia.

The number of tracts needed to achieve stone clearance varied from 2 to 4 in a single renal unit. A total of 154 percutaneous access tracts were established in 66 renal units, thereof $33(50 \%)$ on the right side. Two tracts were used in 48 (72\%), three in $14(22 \%)$, and four in 4 (6\%), respectively. Tracts were positioned in $66(43 \%)$ in the lower pole, in $52(34 \%)$ in the middle pole, and in 36 $(23 \%)$ in the upper pole of the kidneys.

Table 2 Operation and immediate postoperative outcomes

Number of accesses $(n=66)$

2

3

4

Point of entry $(n=154)$

Lower calyces

Mid calyces

Upper calyces

Anesthesia

Spinal

General

Mean operating time, min

Mean preoperative $\mathrm{HB} \mathrm{g} / \mathrm{dL}$

Mean postoperative $\mathrm{HB}$ g/dL

Mean preoperative creatinine $\mathrm{mg} / \mathrm{dL}$

Mean postoperative creatinine $\mathrm{mg} / \mathrm{dL}$

Mean hospital stays (days)

$\begin{array}{ll}48 & 72 \% \\ 14 & 22 \% \\ 4 & 6 \% \\ 66 & 43 \% \\ 52 & 34 \% \\ 36 & 23 \% \\ 58 & 88 \% \\ 8 & 12 \% \\ 79.54 \pm 24.839 \text { SD } & \\ 13.8 \pm 1.36 \text { SD (9.1-16.3) } & \\ 11.1 \pm 1.19 \text { SD (7.8-14.2) } & \\ 1.25 \pm 0.76 \text { SD (0.65-4.3) } & \\ 1.23 \pm 0.56 \text { SD (0.67-3.5) } & \\ 1.5(1-5) & \end{array}$


Table 3 Complications according to the Calvien grading system

\begin{tabular}{ll}
\hline Grade & Percentage \\
\hline Grade 1 & 13 patients $(20 \%)$ \\
Fever & 7 patients $(11 \%)$ \\
Transient renal function derangement & 2 patients $(3 \%)$ \\
Postoperative nausea and vomiting & 4 patients $(6 \%)$ \\
Grade 2 & 9 patients $(13.8 \%)$ \\
Blood transfusion & 6 patients $(9 \%)$ \\
Infection require additional antibiotic & 2 patients $(3 \%)$ \\
Nephrostomy site leakage & 1 patient $(1.5 \%)$ \\
Grade 3(b) & 2 patients $(3 \%)$ \\
Bleeding require termination of the procedure & 1 patient $(1.5 \%)$ \\
Ureteric stone after JJ removal & 1 patient $(1.5 \%)$ \\
Grade 4 & None \\
Grade 5 & None \\
\hline
\end{tabular}

Table 4 Follow-up and adjuvant treatments

\begin{tabular}{ll}
\hline Stone-free after 2 weeks & $56(84.8 \%)$ \\
2nd look PCNL & $2(3 \%)$ \\
URS & $1(1.5 \%)$ \\
Conservative management & $5(7 \%)$ \\
Refused further treatment & $2(3 \%)$ \\
\hline
\end{tabular}

As to laboratory parameters, the mean creatinine did not significantly change from preoperative levels at $24 \mathrm{~h}$ post-PCNL. In contrast, the $\mathrm{Hb}$ level did drop from $13.8 \pm 1.3 \mathrm{gr} / \mathrm{dL}(9.1-16.3)$ to $11.1 \pm 1.1 \mathrm{gr} / \mathrm{dL}(7.8-14.2)$. This was statistically significant with a mean $\mathrm{Hb}$-drop of $2.7 \mathrm{gr} / \mathrm{dL}$. Six (9\%) patients required blood transfusion. The mean hospital stay was 1.5 days (Table 2).

Clavien grade I complications occurred in 13 (20\%) cases: fever in $7(11 \%)$, transient impairment of renal function in $2(3 \%)$, nausea/vomiting in $4(6 \%)$.

Clavien grade II complications occurred in $9(14 \%)$ cases: blood transfusion in 6 (9\%), infection requiring additional antibiotics in $2(3 \%)$, transient urinary leakage in $1(1.5 \%)$.

Calvien grade IIIb complications occurred in $2(3 \%)$ cases: bleeding and abortion of PCNL in 1 (1.5\%), postoperative renal colic after JJ removal and URS in 1 (1.5\%). There were no Clavien IV and V complications (Table 3). We observed no late complications after more than 2 weeks post-PCNL.

$84.8 \%$ of patients were completely stone-free after one session of multitract PCNL. Of the 10 patients with residual fragments, 2 (3\%) underwent a 2nd look PCNL,
1 (1.5\%) URS, 5 (7\%) opted for conservative management, and $2(3 \%)$ refused further treatment (Table 4).

\section{Discussion}

The target of surgical intervention in staghorn stones is to achieve complete stone clearance to prevent recurrences and associated complications [22].

To increase the stone-free rate, many investigators evaluated multitract PCNL, either with standard PCNL or mini-PCNL, or a combination of both. The term "mini-PCNL" has been described by Manohar et al. [19]. With reduced-size instruments, they obtained complete stone clearance in $86 \%$ of cases, albeit with more than $60 \%$ of cases needing multiple tracts.

Cho et al. [23] found that in appropriately chosen patients, a multitract PCNL is safe and efficient. Fei et al. [24] achieved a 78\% stone-free rate in 55 patients with complete staghorn stones who underwent multitract PCNL. They found multitract PCNL crucial to increase total stone clearance and to reduce reliance on supplemental extracorporeal lithotripsy and/or 2nd look PCNL. However, they used a flexible nephroscope to retrieve small peripheral fragments and to confirm stone clearance on the one hand, and to establish the need and location for another puncture on the other hand.

In our study, we achieved an $85 \%$ stone-free rate, which is comparable with other studies (84-89\%) [24-26].

It is noteworthy that the hospital stay was only 1.5 days on average. This is because most of our patients (72\%) needed only two tracts, which were removed usually after $24 \mathrm{~h}$. Patients then were observed for a few hours and discharged on antibiotics.

One shortcoming of our study is that we relied on US and Xray alone to establish stone-free status, which may overestimate stone-free status by $17-35 \%$ [27]. Admittedly, using a CT scan post-procedure to detect residual fragments would be the more accurate method. But again, this is a report from a developing country with limited and restrained resources, and we make use of what we have easily and cost-effectively available.

The rate of blood transfusion in our study was $9.2 \%$, which compares favorably with the literature (7.7-45\%) [21, 22, 28, 29].

The overall complication rate using the modified Clavien-Dindo classification of surgical complications was $36.8 \%$, which corresponds again with other authors' findings (30-41\%) [25, 26]. Most complications were grade I and II. None of our cases developed bleeding that required super-selective angioembolization. Despite controversies in the literature concerning the impact of BMI on the outcome of PCNL, Chen et al. [30] found that BMI has neither affected the stone-free rate nor the 
postoperative complication rate in patients undergoing PCNL. The same findings were observed in our patients.

Limitations to our study are the relatively small number of cases and-as mentioned above-the use of Xray and US KUB, which have the potential to overestimate the stone-free rate. Also, procedures were performed by a highly experienced high-volume stone surgeon. Rates achieved might therefore not be fully representative for general urologists.

\section{Conclusion}

Multitract PCNL is feasible, safe, and efficient in managing staghorn calculi, with acceptable morbidity and complications. When auxiliary combination treatments are not available, multitract standard PCNL remains a good option.

\begin{abstract}
Abbreviations
BMI: Body mass index; CT: Computertomography; dL: Deciliter; ECIRS: Endoscopic combined intrarenal surgery; F: French; gr: Gram; Hb: Hemoglobin; JJ: Double-J; KUB: Kidney, ureter, bladder; mm: Millimeter; OP: Operative; PCN: Percutaneous nephrostomy; PCNL: Percutaneous nephrolitholapaxy; SWL: Extracorporeal shock wave lithotripsy; URS: Ureterorenoscopy; US: Ultrasound; $y$ : Year.
\end{abstract}

\section{Acknowledgements}

Not applicable.

\section{Authors' contributions}

SNM recorded, collected and assisted analyzing the data. AKA recorded, collected and assisted analyzing the data. OAR recorded, collected and assisted analyzing the data and was instrumental in developing the concept of the study. RB developed the concept, initialized the study, and wrote the first draft paper. NB reviewed, edited and submitted the final version. All authors read and approved the final manuscript.

\section{Funding}

Not applicable.

\section{Availability of data and materials}

Not applicable.

\section{Ethics approval and consent to participate}

Ethical approval was obtained from the Iraqi Board for Medical Specialization and consent to participate (Urology) approval number 4691. All participants gave written consent prior to their operation to be included in the study.

\section{Consent to publish}

Not applicable.

\section{Competing interests}

None declared by any of the authors.

\footnotetext{
Author details

${ }^{1}$ Department of Surgery, College of Medicine, University of Sulaymaniyah, Sulaymaniyah, Kurdistan Region, Iraq. ${ }^{2}$ Department of Urology, Sulaymaniyah Surgical Teaching Hospital, Sulaymaniyah, Kurdistan Region, Iraq. ${ }^{3} \mathrm{U}$-merge Ltd. London, Scientific Office, 1 Menandrou Street, 14561 Athens, Greece.

${ }^{4}$ Smart Health Tower, Sulaymaniyah, Kurdistan Region, Iraq.
}

Received: 23 July 2020 Accepted: 12 October 2020

Published online: 26 November 2020

\section{References}

1. Pastore AL, Palleschi G, Silvestri L, Leto A, Ripoli A, Fuschi A, Al Salhi Y, Autieri D, Petrozza V, Carbone A (2016) Combined laparoscopic pyelolithotomy and endoscopic pyelolithotripsy for staghorn calculi: long-term follow-up results from a case series. Therap Adv Urol 8(1):3-8

2. Fink HA, Wilt TJ, Eidman KE et al (2013) Medical management to prevent recurrent nephrolithiasis in adults: a systematic review for an American College of Physicians Clinical Guideline. Ann Int Med 158(7):535-543

3. Singla M, Srivastava A, Kapoor R, Gupta N, Ansari MS et al (2008) Aggressive approach to staghorn calculi safety and efficacy of multiple tracts percutaneous nephrolithotomy. Urology 71:1039-1042

4. Basiri A, Tabibi A, Nouralizadeh A et al (2014) Comparison of safety and efficacy of laparoscopic pyelolithotomy versus percutaneous nephrolithotomy in patients with renal pelvic stones: a randomized clinical trial. J Urol 11(6):1932-1937

5. Haggag YM, Morsy G, Badr MM et al (2013) Comparative study of laparoscopic pyelolithotomy versus percutaneous nephrolithotomy in the management of large renal pelvic stones. Can Urol Assoc J 7(3-4):E171-175

6. Liang T, Zhao C, Wu G, Tang B, Luo X, Lu S, Dong Y, Yang H (2017) Multitract percutaneous nephrolithotomy combined with EMS lithotripsy for bilateral complex renal stones: our experience. BMC Urol 17(1):15

7. Handa RK, Evan AP, Willis LR, Johnson CD, Connors BA, Gao S, Lingeman JE, Matlaga BR, Miller NL, Handa SE (2009) Renal functional effects of multiple-tract percutaneous access. J Endourol 23(12):1951-1956

8. Mandal S, Goel A, Kathpalia R et al (2012) Prospective evaluation of complications using the modified Clavien grading system, and of success rates of percutaneous nephrolithotomy using Guy's Stone Score: a singlecenter experience. Indian J Urol 28:392-398

9. Türk C, Petřík A, Sarica K, Seitz C, Skolarikos A, Straub M, Knoll T (2016) EAU guidelines on interventional treatment for urolithiasis. Eur Urol 69(3):475-482

10. St-Laurent MP, Doizi S, Rosec M, Terrasa JB, Villa L, Traxer O, Cloutier J (2019) Radiation exposure in prone vs. modified supine position during PCNL: results with an anthropomorphic model. Can Urol Ass J 13(8):246

11. Sesmero JA, Delgado MC, de la Cruz Martín B, Rodriguez JM, Fernández DA, Tesedo VR, Way DM, Aceves JG (2017) Small-caliber percutaneous nephrolithotomy (SC-PCNL). Therapeutic decision algorithm. Actas Urológicas Españolas (English Edition) 41(9):552-561

12. Otas D, Milenkovic PD, Predrag N, Djordje A, Bojan C, Uros B, Milan R, Aleksandar J, Skolarikos A (2018) Multi-tract percutaneous nephrolithotomy approach. Hellenic Urol 12:30

13. Elawady H, Mostafa DE, Mahmoud MA, Abuelnaga M, Farouk A, Tawfick A, Elzayat T, Ahmed A (2018) Is multiple tracts percutaneous nephrolithotomy (PCNL) safe modality in the management of complex renal stones? A prospective study: a single-center experience. Afr J Urol 24(4):308-314

14. Tan MAV, Lusaya DG (2019) Multiple vs. single access PCNL. In Endourol Progress, pp 57-63

15. Li JK, Teoh JY, Ng CF (2019) Updates in the endourological management of urolithiasis. Int J Urol 26(2):172-183

16. Aron M, Yadav R, Goel R et al (2005) Multi-tract percutaneous nephrolithotomy for large complete staghorn calculi. Urol Int 75:327-332

17. Hegarty NJ, Desai MM (2006) Percutaneous nephrolithotomy requiring multiple tracts: comparison of morbidity with single-tract procedures. J Endourol 20:753-760

18. Zhong W, Zeng G, Wu W, Chen W, Wu K (2011) Minimally invasive percutaneous nephrolithotomy with multiple mini tracts in a single session in treating staghorn calculi. Urol Res 39:117-122

19. Manohar T, Ganpule AP, Shrivastav P, Desai M (2006) Percutaneous nephrolithotomy for complex caliceal calculi and staghorn stones in children less than five years of age. J Endourol 20:547-551

20. Netto NR Jr, Ikonomidis J, Ikari O, Claro JA (2005) Comparative study of percutaneous access for staghorn calculi. Urology 65:659-662

21. Said SH, Hassan MA, Ali RH, Aghaways I, Kakamad FH, Mohammad KQ (2017) Percutaneous nephrolithotomy; alarming variables for postoperative bleeding. Arab J Urol 15(1):24-29

22. Chen J, Zhou X, Chen Z, Liu L, Jiang L, Chen C, Qi L, Zu X, Chen H (2014) Multiple tracts percutaneous nephrolithotomy assisted by LithoClast master in one session for staghorn calculi: report of 117 cases. Urolithiasis 42(2):165-169 
23. Cho HJ, Lee JY, Kim SW, Hwang TK, Hong SH (2012) Percutaneous nephrolithotomy for complex renal calculi: Is multi-tract approach OK? Can J Urol 19:6360-6365

24. Fei X, Li J, Song Y, Wu B (2014) Single-stage multiple-tract percutaneous nephrolithotomy in the treatment of staghorn stones under total ultrasonography guidance. Urol Int 93(4):411-416

25. Zhao Z, Cui Z, Zeng T, Wan SP, Zeng G (2016) Comparison of 1-stage with 2-stage multiple-tracts mini-percutaneous nephrolithotomy for the treatment of staghorn stones: a matched cohorts analysis. Urology 1(87):46-51

26. Wang Y, Hou Y, Jiang F, Wang Y, Chen Q, Lu Z, Hu J, Wang X, Lu J, Wang C (2014) Standard tract combined with mini-tract in percutaneous nephrolithotomy for renal staghorn calculi. Urol Int 92(4):422-426

27. Ganpule A, Desai M (2009) Fate of residual stones after percutaneous nephrolithotomy: a critical analysis. J Endourol 23(3):399-403
28. Liatsikos EN, Kapoor R, Lee B, Jabbour M, Barbalias G, Smith AD (2005) 'Angular percutaneous renal access.' Multiple tracts through a single incision for staghorn calculous treatment in a single session. Eur Urol 48:832-837

29. Kukreja R, Desai M, Patel S, Bapat S, Desai M (2004) Factors affecting blood loss during percutaneous nephrolithotomy: a prospective study. J Endourol 18:715-722

30. Chen Tsai-Feng, Chen Chung-Hsin, Lee Yuan-Ju (2018) The role of body mass index predicting the outcome of percutaneous nephrolithotomy. Urol Sci 29(5):252

\section{Publisher's Note}

Springer Nature remains neutral with regard to jurisdictional claims in published maps and institutional affiliations.

\section{Submit your manuscript to a SpringerOpen ${ }^{\circ}$ journal and benefit from:}

- Convenient online submission

- Rigorous peer review

- Open access: articles freely available online

- High visibility within the field

- Retaining the copyright to your article

Submit your next manuscript at $\boldsymbol{\nabla}$ springeropen.com 